\title{
Characterizing the temporal dynamics of cortical microcircuits: first and second order kernels for a cortical microcircuit
}

\author{
Philip Ulinski \\ From Nineteenth Annual Computational Neuroscience Meeting: CNS*2010 \\ San Antonio, TX, USA. 24-30 July 2010
}

Neurons in the cerebral cortex form microcircuits that can be described as a network of feedforward and feedback, excitatory and inhibitory loops. It is, consequently, natural to represent cortical microcircuits as a control system (e.g. [1]) with thalamic inputs and outputs to other brain regions. The visual cortex in freshwater turtles contains pyramidal cells that receive inputs from the lateral geniculate nucleus and project to other cortical areas, the geniculate and structures in the brainstem [2]. It also contains at least three populations of inhibitory interneurons called subpial cells, stellate cells and horizontal cells [3]. We [4] have used a large-scale model of turtle visual cortex to characterize this cortex as a control system. However, this model is too large and complex to allow analysis with methods from control and systems theory, so we developed a dynamical systems model that consists of a family of linear nonautonomous ordinary differential equations. The activity of the ith population of neurons, $x_{i}$, is given by the equation (1)

$$
d x_{i}(t) / d t=\sum_{j=1}^{N} a_{i j}(t) x_{j}(t)
$$

The summation is over the $\mathrm{N}$ populations of neurons. The time-dependent coefficients give the time course of synaptic interactions of all neurons in the ith population by all of the neurons in the jth population. The coefficients were determined by fitting the solutions of the equations (1) to the results of simulations using the large-scale model. In this study, we characterized the

Correspondence: pulinski@uchicago.edu

Committee on Computational Neuroscience, University of Chicago, Chicago, IL 60637, USA dynamics of the system (1) to pulses and pairs of pulses in order to determine the impulse response function (or first order kernel) and the higher order kernels of the system. The kernels are important because they describe the underlying temporal dynamics of the system. The first order kernel consists of two peaks, one at about $100 \mathrm{~ms}$ and one at about $600 \mathrm{~ms}$ after a pulse input. Blocking recurrent excitation between pyramidal cells shows that the recurrent excitation is responsible for a large gain in the system. Blocking specific populations of inhibitory interneurons with recurrent excitation intact shows that both feedforward and feedback inhibition control the magnitude of the pyramidal cell response. It also shows that specific populations of inhibitory interneurons interact with each other. The second order (first non-linear) kernel changes it shape as a function of the separation between the two pulses, and becomes zero with interpulse intervals of more than 50 ms. Blocking recurrent excitation between pyramidal cells or all inhibition in the system shows that both recurrent excitation and inhibition make major contributions to the non-linearity in the system. Specific types of inhibitory interneurons contribute to specific temporal phases of the second order kernel. The study suggests that cortical microcircuits have several general features. First, it confirms the concept that recurrent excitation plays a significant role in amplifying cortical inputs. Second, it suggests that the various populations of inhibitory interneurons interact with each other in a complex fashion so that an individual type of interneuron should not be assigned a unique function. Third, it suggests that the structure of the network is not static. It, rather, evolves with time depending on the temporal dynamics of the system. 
Published: 20 July 2010

\section{References}

1. Douglas RJ, Martin KAC: A functional microcircuit for cat visual cortex. J. Physiol 1991, 440:735-769.

2. Colombe JB, Ulinski PS: Temporal dispersion windows in cortical neurons. J. Comput. Neurosci 1999, 7(1):71-87.

3. Colombe JB, Sylvester J, Block J, Ulinski PS: Subpial and stellate cells. Two populations of interneurons in turtle visual cortex. J. Comp. Neurol 2004, 471(3):333-351.

4. Wang W, Campaigne C, Ghosh BK, Ulinski PS: Two cortical circuits control propagating waves in visual cortex. J Comput Neurosci 2005, 19:263-289.

doi:10.1186/1471-2202-11-S1-P36

Cite this article as: Ulinski: Characterizing the temporal dynamics of cortical microcircuits: first and second order kernels for a cortical microcircuit. BMC Neuroscience 2010 11(Suppl 1):P36.

\section{Submit your next manuscript to BioMed Central} and take full advantage of:

- Convenient online submission

- Thorough peer review

- No space constraints or color figure charges

- Immediate publication on acceptance

- Inclusion in PubMed, CAS, Scopus and Google Scholar

- Research which is freely available for redistribution

Submit your manuscript at www.biomedcentral.com/submit 